\title{
BMJ
}

\section{Soft drinks, fructose consumption, and the risk of gout in men: prospective cohort study}

\author{
Hyon K Choi, associate professor of medicine, ${ }^{1}$ Gary Curhan, associate professor of medicine ${ }^{2}$
}

${ }^{1}$ Arthritis Research Centre of Canada, Department of Medicine, Vancouver General Hospital, University of British Columbia, Vancouver, BC V5Z 1L7, Canada

${ }^{2}$ Channing Laboratory, Department of Medicine, Brigham and Women's Hospital, Harvard Medical School, Boston, MA, USA Correspondence to: $\mathrm{H} \mathrm{K}$ Choi hchoi@arthritisresearch.ca

doi:10.1136/bmj.39449.819271.BE

\section{ABSTRACT}

Objective To examine the relation between intake of sugar sweetened soft drinks and fructose and the risk of incident gout in men.

Design Prospective cohort over 12 years.

Setting Health professionals follow-up study.

Participants 46393 men with no history of gout at baseline who provided information on intake of soft drinks and fructose through validated food frequency questionnaires.

Main outcome measure Incident cases of gout meeting the American College of Rheumatology survey criteria for gout. Results During the 12 years of follow-up 755 confirmed incident cases of gout were reported. Increasing intake of sugar sweetened soft drinks was associated with an increasing risk of gout. Compared with consumption of less than one serving of sugar sweetened soft drinks a month the multivariate relative risk of gout for $5-6$ servings a week was 1.29 (95\% confidence interval 1.00 to 1.68 ), for one serving a day was 1.45 (1.02 to 2.08), and for two or more servings a day was 1.85 (1.08 to 3.16; P for trend $=0.002$ ). Diet soft drinks were not associated with risk of gout ( $P$ for trend=0.99). The multivariate relative risk of gout according to increasing fifths of fructose intake were $1.00,1.29,1.41,1.84$, and 2.02 (1.49 to 2.75; P for trend 0.001 ). Other major contributors to fructose intake such as total fruit juice or fructose rich fruits (apples and oranges) were also associated with a higher risk of gout ( $P$ values for trend 10.05 ).

Conclusions Prospective data suggest that consumption of sugar sweetened soft drinks and fructose is strongly associated with an increased risk of gout in men.

Furthermore, fructose rich fruits and fruit juices may also increase the risk. Diet soft drinks were not associated with the risk of gout.

\section{INTRODUCTION}

Gout is the most common inflammatory arthritis in men. ${ }^{12}$ The overall burden from this disease remains substantial and is growing. ${ }^{3}$ Identifying the risk factors that are modifiable with available measures is an important first step in the prevention and management of this painful condition. ${ }^{4}$ The doubling of the prevalence $^{5}$ and incidence ${ }^{6}$ of gout over the past few decades in the United States ${ }^{34}$ coincided with a substantial increase in the consumption of soft drinks and fructose. ${ }^{7}$ For example, soft drink consumption in the US increased by $61 \%$ in adults from 1977 to $1997,{ }^{7}$ and sugar sweetened soft drinks represent the largest single food source of calories in the US diet. ${ }^{78}$ Fructose consumption has also increased dramatically since the introduction of commercially produced high fructose corn syrup in $1967,{ }^{9}$ and its yearly per capita use has increased from $0 \mathrm{~kg}$ to $29 \mathrm{~kg},{ }^{10-12}$ whereas naturally occurring fructose consumption has remained relatively stable. ${ }^{13}$

Conventional dietary recommendations for gout have focused on restriction of purine and alcohol intake but with no restriction of sugar sweetened soft drinks. ${ }^{14}{ }^{15}$ Although such soft drinks contain low levels of purine they contain large amounts of fructose, which is the only carbohydrate known to increase uric acid levels. ${ }^{12-19}$ In humans, acute oral or intravenous administration of fructose results in a rapid increase in serum levels of uric acid through accentuated degradation of purine nucleotides ${ }^{16}$ and increased purine synthesis. ${ }^{2021}$ This urate raising effect was found to be exaggerated in people with hyperuricaemia ${ }^{18}$ or a history of gout. ${ }^{17}$ It is unknown, however, if this acute effect is sustained on a long term basis and eventually translates into an increased risk of gout. We prospectively evaluated the relation between intake of sugar sweetened soft drinks and fructose and the incidence of gout in a cohort of 46393 men with no history of gout.

\section{METHODS}

The health professionals follow-up study is an ongoing longitudinal study of 51529 male dentists, optometrists, osteopaths, pharmacists, podiatrists, and veterinarians. The men are predominantly white (91\%) and were aged 40 to 75 years in 1986. The participants returned a mailed questionnaire in 1986 on diet, medical history, and drugs. Of the 49166 men who provided complete information on intake of sugar sweetened soft drinks, $2773(5.6 \%)$ reported a history of gout on the baseline questionnaire. We excluded these prevalent cases at baseline from this analysis. The follow-up rate exceeded $90 \%$ for each two year period. Participants who failed to respond to a questionnaire during one follow-up cycle were not removed from the study; they were included in the next mailing of the 
questionnaire (they could skip answering a questionnaire but then answer the next).

\section{Assessment of dietary intake}

To assess dietary intake including that of soft drinks we used a validated food frequency questionnaire that inquired about the average use of more than 130 foods and beverages during the previous year. ${ }^{2223}$ The baseline dietary questionnaire was completed in 1986 and was updated every four years. On all questionnaires participants were asked how often on average during the previous year they had consumed sugar sweetened soft drinks ("Coke, Pepsi, or other cola with sugar," "caffeine-free Coke, Pepsi, or other cola with sugar," and "other carbonated beverages with sugar") and diet soft drinks ("low-calorie cola with caffeine," "low-calorie caffeine-free cola," and "other low-calorie beverages"). We also assessed different types of fruits and fruit juices. We summed the intake of single items to create a total for consumption of sugar sweetened soft drinks, diet soft drinks, and fruit juice.

Participants could choose from nine frequency responses (never, 1-3 a month, 1 a week, 2-4 a week, 5-6 a week, 1 a day, 2-3 a day, 4-5 a day, and $\geq 6$ a day). We computed nutrient intakes by multiplying the frequency response by the nutrient content of the specified portion sizes. ${ }^{23}$ Values for nutrients were derived from the US Department of Agriculture sources $^{24}$ and supplemented with information from manufacturers.

Fructose is a monosaccharide. Half of the disaccharide sucrose is fructose, which is split from sucrose in the small intestine. Therefore total fructose intake is equal to the intake of free fructose plus half the intake of sucrose. In this cohort at baseline orange juice, sugar sweetened soft drinks, apples, raisins, and oranges contributed $54.2 \%$ of monosaccharide fructose $(15.9 \%$,
15.5\%, 14.5\%, 5.2\%, 3.2\%, respectively). Food intake assessed by this dietary questionnaire has been validated previously against two one week diet records in this cohort. ${ }^{2225}$ Specifically, the correlation coefficients between questionnaires and diet records were 0.84 for sugar sweetened cola, 0.73 for diet cola, 0.55 for other sugar sweetened soft drinks, 0.74 for other diet soft drinks, 0.78 for orange juice, 0.70 for apples, 0.76 for oranges, 0.59 for raisins, and 0.89 for other fruit juices. $^{25}$

\section{Assessment of non-dietary factors}

At baseline and every two years the participants provided information on weight, regular use of drugs (including diuretics), and medical conditions (including hypertension and chronic renal failure). ${ }^{26} \mathrm{We}$ calculated body mass index by dividing weight in kilograms by the square of the height in metres.

\section{Ascertainment of incident cases of gout}

We ascertained incident cases of gout using the survey criteria of the American College of Rheumatology, as previously described. ${ }^{2}$ Briefly, on each biennial questionnaire participants indicated whether they had received a diagnosis of gout from a doctor. We mailed a supplementary questionnaire to those participants with self reported incident gout diagnosed from 1986 onwards to confirm the report and to ascertain the American College of Rheumatology criteria for gout. ${ }^{227}$ Our primary end point was incident cases of gout that met six or more of the 11 criteria for gout. ${ }^{227}$ To confirm the validity of the criteria in our cohort we reviewed the medical records from a sample of 50 of the men who had reported having gout. The concordance rate between the criteria and the medical record review was $94 \%(47 / 50) .^{2}$ We further evaluated the robustness of our results by using other outcome definitions for

\begin{tabular}{|c|c|c|c|c|c|c|c|c|c|c|c|}
\hline \multirow[b]{2}{*}{ Variable } & \multicolumn{6}{|c|}{ Sugar sweetened soft drink intake (servings/day) } & \multicolumn{5}{|c|}{ Fifths of free fructose intake (\% of energy, median) } \\
\hline & $\ll 1 /$ month & $\begin{array}{l}\text { 1/month- } \\
1 / \text { week }\end{array}$ & 2-4/week & $5-6 /$ week & $1 /$ day & $\geq 2 /$ day & 1st (2.6) & 2nd (3.8) & $3 r d(4.7)$ & 4th (5.8) & 5 th (7.9) \\
\hline No of participants & 20205 & 13247 & 4661 & 4802 & 2420 & 1058 & 9278 & 9279 & 9279 & 9279 & 9278 \\
\hline Mean age (years) & 56 & 54 & 53 & 52 & 51 & 49 & 54 & 55 & 55 & 54 & 54 \\
\hline Mean body mass index $\left(\mathrm{kg} / \mathrm{m}^{2}\right)$ & 24.9 & 24.8 & 24.8 & 24.8 & 24.8 & 25.1 & 25.1 & 24.9 & 24.8 & 24.7 & 24.6 \\
\hline Diuretic use & 10 & 9 & 10 & 9 & 10 & 9 & 9 & 9 & 10 & 10 & 10 \\
\hline History of hypertension & 22 & 20 & 19 & 19 & 21 & 23 & 21 & 20 & 20 & 20 & 22 \\
\hline History of chronic renal failure & 0.1 & 0.1 & 0.1 & 0.1 & 0.2 & 0.1 & 0.1 & 0.1 & 0.1 & 0.1 & 0.1 \\
\hline \multicolumn{12}{|l|}{ Mean dietary intake: } \\
\hline Alcohol (g/day) & 12 & 11 & 11 & 10 & 11 & 12 & 19 & 13 & 11 & 8 & 6 \\
\hline Total meat (servings/day) & 1.2 & 1.4 & 1.5 & 1.6 & 1.7 & 1.8 & 1.6 & 1.5 & 1.4 & 1.2 & 1.1 \\
\hline Seafood (servings/day) & 0.4 & 0.4 & 0.4 & 0.4 & 0.3 & 0.3 & 0.3 & 0.4 & 0.4 & 0.4 & 0.4 \\
\hline Low fat dairy foods (servings/day) & 1.0 & 1.0 & 1.0 & 0.9 & 0.9 & 0.7 & 0.9 & 1.0 & 1.0 & 1.0 & 0.9 \\
\hline High fat dairy foods (servings/day) & 1.1 & 1.3 & 1.3 & 1.5 & 1.6 & 1.7 & 1.5 & 1.3 & 1.2 & 1.1 & 1.0 \\
\hline Total caffeine (mg/day) & 217 & 232 & 231 & 244 & 248 & 269 & 292 & 249 & 224 & 201 & 174 \\
\hline Free fructose (\% of energy) & 4.7 & 4.8 & 5.2 & 5.8 & 6.7 & 9.7 & 2.5 & 3.8 & 4.7 & 5.9 & 8.6 \\
\hline Total fructose (\% of energy) & 8.4 & 9.0 & 9.8 & 10.8 & 12.0 & 15.9 & 5.7 & 7.6 & 9.0 & 10.4 & 13.8 \\
\hline
\end{tabular}

Data, except age, were directly standardised to age distribution of each study sample. 
gout, including self reported gout diagnosed by a doctor (most sensitive) and cases that reported a tophus or crystal proved gout (most specific).

\section{Statistical analysis}

We computed person time of follow-up for each participant from the return date of the 1986 questionnaire to the date of diagnosis of gout, death from any cause, or the end of the study period (1998), whichever came first. Men who had reported having gout on previous questionnaires were excluded from subsequent follow-up.

To represent long term dietary intake patterns of individual participants we used cumulative average intakes on the basis of the information from questionnaires completed in 1986,1990 , and $1994 .{ }^{28-30}$ For example, the incidence of gout from 1986 to 1990 was related to the soft drink intake reported on the 1986 questionnaire, and incidence from 1990 to 1994 was related to the average intake reported on the 1986 and 1990 questionnaires.

We used Cox proportional hazards modelling (PROC PHREG) to estimate the relative risk for incident gout in all multivariate analyses (SAS Institute). For these analyses we categorised soft drink consumption into six frequency groups: less than 1 serving a month, 1 serving a month to 1 a week, 2-4 servings a week, 5-6 servings a week, 1 serving a day, and 2 or more servings a day. We categorised free fructose and total fructose intake into fifths for percentage of energy (nutrient density ${ }^{31}$ ). Multivariate models for soft drink consumption were adjusted for age (continuous), total energy intake (continuous), alcohol intake (seven categories), body mass index (six categories), use of diuretics (thiazide or furosemide (frusemide)) (yes or no), history of hypertension (yes or no), history of chronic renal failure (yes or no), and average daily intake of meats, seafood, purine rich vegetables, dairy foods, and total vitamin C (fifths). ${ }^{2628}$ We evaluated the potential impact of coffee intake, ${ }^{32}$ caffeine intake, and fructose intake by entering each term (five categories for coffee intake and fifths for the others) into the multivariate model for soft drink consumption. In multivariate nutrient density models for fructose intake, ${ }^{31}$ we simultaneously included energy intake, the percentages of energy derived from protein and carbohydrate (or non-fructose carbohydrate), intake of vitamin $\mathrm{C}$ and alcohol, and other non-dietary variables. The coefficients from these models can be interpreted as the estimated effect of substituting a specific percentage of energy from fructose for the same percentage of energy from nonfructose carbohydrate (or fat)..$^{31}$

We assessed trends in gout risk across categories of soft drink or fructose intake in Cox proportional hazards models by using the median values of intake

Table 2| Relative risk of incident gout in men according to levels of soft drink consumption

\begin{tabular}{|c|c|c|c|c|c|c|c|}
\hline \multirow[b]{2}{*}{ Variable } & \multicolumn{6}{|c|}{ Frequency of intake (servings) } & \multirow[b]{2}{*}{$P$ for trend } \\
\hline & $\ll 1 /$ month & $1 /$ month-1/week & 2-4/week & 5-6/week & $1 /$ day & $\geq 2 /$ day & \\
\hline \multicolumn{8}{|l|}{ Sugar sweetened soft drinks: } \\
\hline No of cases & 279 & 251 & 82 & 88 & 39 & 16 & - \\
\hline Person years & 158891 & 151173 & 53086 & 47433 & 20485 & 7392 & - \\
\hline $\begin{array}{l}\text { Age, } \mathrm{BMI} \text {, alcohol, and energy } \\
\text { adjusted relative risk }(95 \% \mathrm{Cl})\end{array}$ & $1.0^{\star}$ & $1.00(0.84$ to 1.19$)$ & $1.00(0.78$ to 1.29$)$ & 1.30 (1.01 to 1.67$)$ & 1.44 (1.02 to 2.04$)$ & 1.78 (1.06 to 2.98$)$ & 0.002 \\
\hline Multivariate relative risk $(95 \% \mathrm{Cl}) \dagger$ & $1.0^{\star}$ & $1.00(0.84$ to 1.20$)$ & 0.99 (0.77 to 1.29$)$ & $1.29(1.00$ to 1.68$)$ & 1.45 (1.02 to 2.08$)$ & 1.85 (1.08 to 3.16$)$ & 0.002 \\
\hline \multicolumn{8}{|l|}{ Diet soft drinks: } \\
\hline No of cases & 228 & 174 & 87 & 113 & 92 & 60 & - \\
\hline Person years & 161129 & 96334 & 44987 & 59628 & 46434 & 28148 & - \\
\hline $\begin{array}{l}\text { Age, } \mathrm{BMI} \text {, alcohol, and energy } \\
\text { adjusted relative risk }(95 \% \mathrm{Cl})\end{array}$ & $1.0^{\star}$ & $1.18(0.96$ to 1.44$)$ & $1.18(0.92$ to 1.51$)$ & 1.13 (0.90 to 1.43$)$ & 1.14 (0.89 to 1.47$)$ & $1.23(0.91$ to 1.66$)$ & 0.27 \\
\hline Multivariate relative risk† $(95 \% \mathrm{Cl})$ & $1.0^{\star}$ & $1.18(0.97$ to 1.45$)$ & 1.15 (0.89 to 1.48$)$ & 1.09 (0.86 to 1.38$)$ & 1.07 (0.83 to 1.38$)$ & 1.12 (0.82 to 1.52$)$ & 0.99 \\
\hline \multicolumn{8}{|l|}{ Sweetened cola: } \\
\hline No of cases & 326 & 261 & 83 & 51 & $34 \ddagger$ & - & - \\
\hline Person years & 192060 & 147785 & 47607 & 31611 & $18680 \ddagger$ & - & - \\
\hline $\begin{array}{l}\text { Age, } \mathrm{BMI} \text {, alcohol, and energy } \\
\text { adjusted relative risk }(95 \% \mathrm{Cl})\end{array}$ & $1.0^{\star}$ & $1.09(0.92$ to 1.29$)$ & $1.18(0.93$ to 1.52$)$ & 1.17 (0.86 to 1.58$)$ & $1.47(1.02$ to 2.12$) \S$ & - & 0.04 \\
\hline Multivariate relative risk† $(95 \% \mathrm{Cl})$ & $1.0^{\star}$ & 1.09 (0.92 to 1.29$)$ & $1.18(0.92$ to 1.52$)$ & $1.16(0.85$ to 1.58$)$ & 1.50 (1.02 to 2.19$) \S$ & - & 0.07 \\
\hline \multicolumn{8}{|l|}{ Other sweetened soft drinks: } \\
\hline No of cases & 407 & 277 & 43 & 9 & $13 \ddagger$ & - & - \\
\hline Person years & 245712 & 157526 & 22986 & 5706 & $3152 \ddagger$ & - & - \\
\hline $\begin{array}{l}\text { Age, } \mathrm{BMI} \text {, alcohol, and energy } \\
\text { adjusted relative risk }(95 \% \mathrm{Cl})\end{array}$ & $1.0^{\star}$ & 1.18 (1.01 to 1.39$)$ & $1.34(0.97$ to 1.85$)$ & 1.09 (0.56 to 2.12$)$ & $2.89(1.65$ to 5.06$) \ddagger$ & - & 0.002 \\
\hline Multivariate relative risk $\dagger(95 \% \mathrm{Cl})$ & $1.0^{\star}$ & 1.15 (0.96 to 1.37$)$ & $1.28(0.92$ to 1.80$)$ & 1.05 (0.54 to 2.07$)$ & $2.76(1.55$ to 4.89$) \ddagger$ & - & 0.008 \\
\hline
\end{tabular}

$\mathrm{BMI}=$ body mass index. Number of cases may not add up to 755 because of missing data.

*Referent.

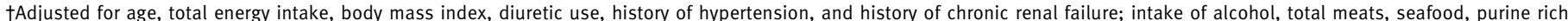
vegetables, dairy foods, and total vitamin C; and sweetened soft drinks, diet soft drinks, sweetened cola, and other sweetened soft drinks.

$\ddagger$ Values relate to one or more servings per day. 


\begin{tabular}{|c|c|c|c|c|c|c|}
\hline \multirow[b]{2}{*}{ Variable } & \multicolumn{5}{|c|}{ Fifths of fructose intake } & \multirow[b]{2}{*}{$P$ for trend } \\
\hline & $1 \mathrm{st}$ & 2nd & $3 r d$ & 4th & 5 th & \\
\hline Free fructose (\% of energy): & $<3.5$ & $3.5-4.4$ & $4.5-5.3$ & $5.4-6.6$ & $>6.6$ & \\
\hline No of cases & 152 & 154 & 146 & 160 & 143 & - \\
\hline Person years & 87136 & 87618 & 87818 & 88050 & 87839 & - \\
\hline $\begin{array}{l}\text { Age, } \mathrm{BMI} \text {, alcohol, and energy } \\
\text { adjusted relative risk }(95 \% \mathrm{Cl})\end{array}$ & 1.0 & $1.19(0.95$ to 1.49$)$ & 1.21 (0.96 to 1.53$)$ & $1.45(1.15$ to 1.83$)$ & $1.43(1.12$ to 1.83$)$ & 0.001 \\
\hline $\begin{array}{l}\text { Multivariate relative risk* } \\
(95 \% \mathrm{Cl})\end{array}$ & 1.0 & 1.26 (1.00 to 1.59$)$ & 1.33 (1.04 to 1.70$)$ & 1.68 (1.30 to 2.16$)$ & 1.81 (1.38 to 2.38$)$ & $<0.001$ \\
\hline $\begin{array}{l}\text { Multivariate relative risk† } \\
(95 \% \mathrm{Cl})\end{array}$ & 1.0 & $1.29(1.02$ to 1.64$)$ & 1.41 (1.09 to 1.82$)$ & $1.84(1.40$ to 2.41$)$ & $2.02(1.49$ to 2.75$)$ & $<0.001$ \\
\hline Total fructose $\ddagger$ (\% of energy): & $<6.9$ & $6.9-8.5$ & $8.6-10.0$ & $10.1-11.8$ & $>11.8$ & \\
\hline No of cases & 186 & 139 & 153 & 137 & 140 & - \\
\hline Person years & 87050 & 87761 & 87815 & 88087 & 87748 & - \\
\hline $\begin{array}{l}\text { Age, } \mathrm{BMI} \text {, alcohol, and energy } \\
\text { adjusted relative risk }(95 \% \mathrm{Cl})\end{array}$ & 1.0 & $0.90(0.72$ to 1.13$)$ & 1.11 (0.88 to 1.39$)$ & $1.08(0.85$ to 1.37$)$ & 1.24 (0.97 to 1.57$)$ & 0.04 \\
\hline $\begin{array}{l}\text { Multivariate relative risk* } \\
(95 \% \mathrm{Cl})\end{array}$ & 1.0 & $0.96(0.76$ to 1.21$)$ & $1.20(0.95$ to 1.53$)$ & $1.25(0.96$ to 1.61$)$ & $1.52(1.15$ to 2.01$)$ & 0.001 \\
\hline $\begin{array}{l}\text { Multivariate relative risk } \dagger \\
(95 \% \mathrm{Cl})\end{array}$ & 1.0 & 0.98 (0.77 to 1.25$)$ & 1.29 (1.00 to 1.67$)$ & 1.41 (1.06 to 1.88$)$ & 1.81 (1.31 to 2.50$)$ & $<0.001$ \\
\hline \multicolumn{7}{|c|}{$\begin{array}{l}\text { BMI=body mass index. } \\
\text { *Adjusted for age, total energy intake, body mass index, diuretic use, history of hypertension, history of renal failure; intake of alcohol and total } \\
\text { vitamin C; and percentage of energy from non-fructose carbohydrate and total protein to estimate effects of substituting fructose for equivalent energy } \\
\text { from fat. } \\
\text { †Adjusted for age, total energy intake, body mass index, diuretic use, history of hypertension, history of renal failure; intake of alcohol and total } \\
\text { vitamin C; and percentage of energy from total carbohydrate to estimate effects of fructose for equivalent energy from other carbohydrates. } \\
\text { †Free fructose plus half the amount of sucrose. }\end{array}$} \\
\hline
\end{tabular}

for each category to minimise the influence of outliers. To assess possible effect modification we did analyses stratified by body mass index $(<25 \mathrm{~kg} / \mathrm{m} 2 \mathrm{v} \geq 25 \mathrm{~kg} /$ $\mathrm{m} 2)$, alcohol use (yes or no), and dairy intake $(\leq 1.6$ servings/day (median value) $v>1.6$ servings/day). We tested the significance of the interaction with a likelihood ratio test by comparing a model with the main effects of each intake and the stratifying variable and the interaction terms with a reduced model with only the main effects. For all relative risks we calculated $95 \%$ confidence intervals. $P$ values are two sided.

\section{RESULTS}

During 12 years of follow-up of 46393 eligible men from the health professionals follow-up study, we documented 755 newly diagnosed cases of gout meeting the American College of Rheumatology criteria. Table 1 shows the characteristics of the cohort according to baseline levels of sugar sweetened soft drinks and free fructose consumption. With increasing consumption of sugar sweetened soft drinks the intake of caffeine, fructose, meats, and high fat dairy foods tended to increase whereas mean age and low fat dairy intake tended to decrease (table 1). With increasing consumption of free fructose the body mass index and intake of alcohol, caffeine, meats, and high fat dairy foods tended to decrease (table 1).

\section{Sugar sweetened soft drinks and incident gout}

Increasing intake of sugar sweetened soft drinks was associated with an increasing risk of gout (table 2). Compared with the reference consumption level of less than one serving a month, the multivariate relative risk of gout for 5-6 servings a week was $1.29(95 \%$ confidence interval 1.00 to 1.68 ), for one serving a day was 1.45 (1.02 to 2.08), and for two or more servings a day was 1.85 (1.08 to 3.16; P for trend 0.002). In contrast, diet soft drinks were not associated with risk of gout ( $\mathrm{P}$ for trend 0.99 ). When additional adjustments were made for caffeine or coffee intake, these results did not change materially. After adjusting for fructose in intakes of fifths, however, the association between the intake of sugar sweetened soft drinks and risk of gout was attenuated and no longer significant $(\mathrm{P}$ for trend $0.10)$.

\section{Fructose intake and incident gout}

Increasing fructose intake was associated with increasing risk of gout (table 3). Compared with men in the lowest fifth of free fructose intake, the multivariate relative risk of gout in the highest fifth when substituting fructose for the equivalent energy from fat was 1.81 (95\% confidence interval 1.38 to 2.38 ; $\mathrm{P}$ for trend $<0.001)$. The corresponding relative risk increased after adjustment for total carbohydrate intake to reflect the substitution effect of fructose for other types of carbohydrates (multivariate relative risk 2.02, 1.49 to 2.75; P for trend $<0.001)$. Similarly, higher total fructose intake was significantly associated with increasing risk of gout ( $\mathrm{P}$ for trend $\leq 0.001$; table 3 ). When fructose intake was used as a continuous variable, the multivariate relative risk for a $5 \%$ increment in energy from free fructose, as compared with equivalent energy intake from other types of carbohydrates, was $2.10(1.53$ to 2.77$)$ and the 
corresponding relative risk for total fructose was 1.52 (1.23 to 1.88$)$.

Among other foods and beverages contributing fructose, total fruit juice intake was associated with risk of gout (table 4). Compared with men who consumed less than a glass of fruit juice a month, the multivariate relative risk for gout in those consuming two or more glasses a day was 1.81 (95\% confidence interval 1.12 to 2.93 ; table 4). The corresponding multivariate relative risk for orange juice or apple juice was 1.82 (1.11 to 3.00). Similarly, intake of oranges or apples was associated with risk of gout. Compared with men who consumed less than one apple or orange a month, the multivariate relative risk of gout in those who consumed one apple or orange a day was 1.64 (1.05 to 2.56). The corresponding multivariate relative risk for orange intake alone was 1.55 (1.02 to 2.36) and for apple intake alone was 1.48 (0.98 to 2.25). No other individual fructose rich food items were associated with risk of gout, although their frequency of consumption was relatively low.

\section{Risk according to body mass index, alcohol use, and dairy intake}

Stratified analyses were done to evaluate whether the association between consumption of sugar sweetened soft drinks and fructose and risk of gout varied according to body mass index, alcohol use, and dairy intake. Relative risks from these stratified analyses consistently suggested associations similar to those from the main analyses, and no significant interaction was found with these variables (all $\mathrm{P}$ values for interaction $>0.63$; figure).

\section{Other definitions of dietary exposure and gout}

When analyses were repeated using baseline dietary intake (1986 questionnaire) and updated dietary intakes every four years without cumulative averaging, the results remained significant. The multivariate relative risk between the extreme fifths of free fructose substituting for other carbohydrates with baseline dietary intake was 1.81 (95\% confidence interval 1.36 to $2.41 ; \mathrm{P}$ for trend $<0.001)$ and with updated information without cumulative averaging was 1.93 (1.44 to 2.60; P for trend $<0.001)$. The corresponding multivariate relative risks for substituting free fructose for fat were 1.59 (1.23 to 2.06 ; $\mathrm{P}$ for trend $<0.001)$ and 1.77 (1.35 to 2.31 ; P for trend $<0.001)$.

With other case definitions of gout, the magnitudes of associations tended to increase as specificity of the case definition increased, but null associations remained null. For example, as the definition became more specific, going from self reported gout $(n=1676)$, to gout defined by the American College of Rheumatology criteria $(\mathrm{n}=755)$, to tophaceous or crystal proved gout $(n=124)$, the multivariate relative risks between the extreme fifths of free fructose intake substituting for other carbohydrates were, respectively, 1.65 (1.35 to 2.01), 2.02 (1.49 to 2.75 ), and 2.25 (1.03 to 4.93 ). The corresponding multivariate relative risks for substituting free fructose for fat were 1.54 (1.29 to 1.85$), 1.81$ (1.38 to 2.38 ), and 2.23 (1.10 to 4.54 ).

Table 4 | Relative risk of incident gout in men according to intake of other fructose rich foods and beverages

\begin{tabular}{|c|c|c|c|c|c|c|c|}
\hline \multirow[b]{2}{*}{ Variable } & \multicolumn{6}{|c|}{ Frequency of intake } & \multirow[b]{2}{*}{ P for trend } \\
\hline & $\ll 1 /$ month & $1 /$ month-1/week & 2-4/week & $5-6 /$ week & $1 /$ day & $\geq 2 /$ day & \\
\hline \multicolumn{8}{|l|}{ Total fruit juices* (small glass): } \\
\hline No of cases & 31 & 137 & 116 & 191 & 236 & 43 & - \\
\hline Person years & 26590 & 85201 & 61964 & 107415 & 129859 & 26144 & - \\
\hline $\begin{array}{l}\text { Age, } \mathrm{BMI} \text {, alcohol, and energy } \\
\text { adjusted relative risk }(95 \% \mathrm{Cl})\end{array}$ & $1.0 \dagger$ & 1.37 (0.92 to 2.02$)$ & 1.64 (1.10 to 2.45$)$ & 1.60 (1.09 to 2.35$)$ & 1.76 (1.20 to 2.57$)$ & 1.83 (1.14 to 2.93$)$ & 0.008 \\
\hline Multivariate relative risk $\ddagger(95 \% \mathrm{Cl})$ & $1.0 \dagger$ & 1.34 (0.91 to 1.99$)$ & $1.57(1.05$ to 2.35$)$ & 1.55 (1.05 to 2.30$)$ & 1.74 (1.18 to 2.56$)$ & 1.81 (1.12 to 2.93$)$ & 0.01 \\
\hline \multicolumn{8}{|l|}{ Orange or apple juice (small glass): } \\
\hline No of cases & 49 & 208 & 130 & 186 & 155 & 25 & - \\
\hline Person years & 38720 & 119388 & 65710 & 104037 & 93891 & 14630 & - \\
\hline $\begin{array}{l}\text { Age, } \mathrm{BMI} \text {, alcohol, and energy } \\
\text { adjusted relative risk }(95 \% \mathrm{Cl})\end{array}$ & $1.0 \dagger$ & 1.40 (1.03 to 1.92$)$ & 1.61 (1.16 to 2.25$)$ & 1.56 (1.13 to 2.15$)$ & $1.53(1.10$ to 2.11$)$ & 1.78 (1.09 to 2.91$)$ & 0.04 \\
\hline Multivariate relative risk $\ddagger(95 \% \mathrm{Cl})$ & $1.0 \dagger$ & 1.41 (1.03 to 1.93$)$ & 1.59 (1.14 to 2.23$)$ & 1.55 (1.12 to 2.15$)$ & 1.53 (1.09 to 2.13$)$ & 1.82 (1.11 to 3.00$)$ & 0.05 \\
\hline \multicolumn{8}{|l|}{ Orange or apple: } \\
\hline No of cases & 25 & 217 & 126 & 247 & $139 \S$ & - & - \\
\hline Person years & 16520 & 124376 & 77146 & 139438 & $79968 \S$ & - & - \\
\hline $\begin{array}{l}\text { Age, } \mathrm{BMI} \text {, alcohol, and energy } \\
\text { adjusted relative risk }(95 \% \mathrm{Cl})\end{array}$ & $1.0 \dagger$ & 1.20 (0.79 to 1.83$)$ & 1.17 (0.75 to 1.81$)$ & 1.34 (0.88 to 2.04$)$ & $\begin{array}{c}1.43(0.93 \text { to } \\
2.21) \S\end{array}$ & - & 0.05 \\
\hline Multivariate relative risk $\ddagger(95 \% \mathrm{Cl})$ & $1.0 \dagger$ & 1.24 (0.82 to 1.89$)$ & $1.22(0.79$ to 1.90$)$ & $1.43(0.94$ to 2.19$)$ & $\begin{array}{c}1.64(1.05 \text { to } \\
2.56) \S\end{array}$ & - & 0.006 \\
\hline
\end{tabular}

BMI=body mass index. Number of gout cases does not add up to total because of missing data.

*Includes orange juice, apple juice, grape juice, and other fruit juices.

†Referent.

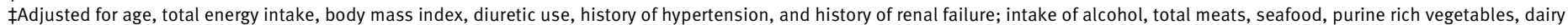
foods, total vitamin C, and the beverages presented in this table and table 2 .

$\S$ Values relate to one or more servings per day. 


\section{DISCUSSION}

In this large prospective study of men we found that the risk of incident gout increased with increasing intake of sugar sweetened soft drinks. The risk was significantly increased with an intake level of 5-6 servings a week and the risk rose with increasing intake. The risk of incident gout was $85 \%$ higher among men who consumed two or more servings of sugar sweetened soft drinks daily compared with those who consumed less than one serving monthly. In contrast, diet soft drinks were not associated with the risk of incident gout. Furthermore, the risk of gout was significantly increased with increasing fructose intake; the risk of gout was about twice as high among men in the highest fifth of free fructose consumption than among men in the lowest fifth. These associations were independent of dietary and other risk factors for gout such as body mass index, age, hypertension, diuretic use, alcohol intake, and history of chronic renal failure. The current study provides prospective evidence that fructose and fructose rich foods are important risk factors to be considered in the primary prevention of gout in men.

We found that the risk of incident gout associated with fructose or fructose rich foods was substantial. For example, the risk of gout posed by the highest fifth of fructose intake was comparable to that seen with alcohol intake of $30 \mathrm{~g}$ to $50 \mathrm{~g}$ daily reported in this cohort (relative risk 1.96) ${ }^{28}$ Similarly, the magnitudes of risk posed by sugar sweetened soft drinks or fruit juices were slightly larger than that of spirits (relative risk for $\geq 2$ servings a day, 1.60 ) in the same cohort. ${ }^{28}$ Furthermore, the increased risk of gout per serving was comparable to individual alcoholic beverages $35 \%$ for sugar sweetened soft drink and $49 \%$ and $15 \%$ for beer and spirits ${ }^{28}$. Because the urate raising effect of fructose is greatest in patients with gout or hyperuricaemia ${ }^{16-19}$ our findings may be even more relevant in those patients.

Interestingly, fructose shares ethanol's urate raising mechanism that induces uric acid production by increasing ATP degradation to AMP, a precursor of uric acid. ${ }^{416213334}$ Fructose phosphorylation in the liver uses ATP, and the accompanying phosphate depletion limits regeneration of ATP from ADP, which in turn serves as substrate for the catabolic pathway to uric acid formation. ${ }^{35}$ Thus minutes after an infusion of fructose, plasma (and later urinary) uric acid concentrations are increased. ${ }^{16}$ In conjunction with purine nucleotide depletion, rates of purine synthesis de novo are accelerated, thus potentiating uric acid production. ${ }^{20}$ In contrast, glucose and other simple sugars do not have the same effect. ${ }^{12}$

Furthermore, fructose could indirectly increase the level of serum uric acid and the risk of gout by increasing insulin resistance and circulating insulin levels. ${ }^{13}$ Experimental studies in animal models and from short term feeding trials among humans suggest that higher fructose intake contributes to insulin resistance, impaired glucose tolerance, and hyperinsulinaemia. ${ }^{36-39}$ For example, rats fed a diet containing 35\% of energy as fructose for four weeks
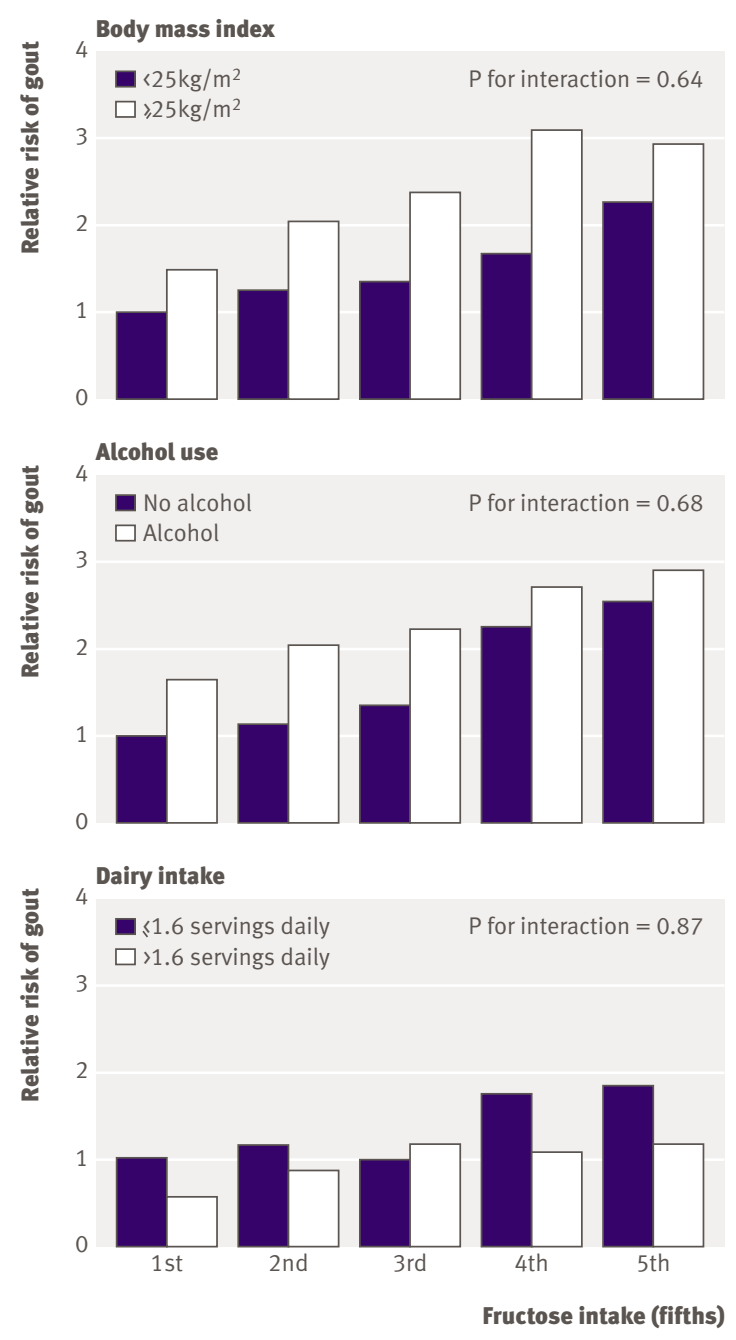

Multivariate relative risk of incident gout in $\mathbf{4 6 3 9 3}$ men from health professionals follow-up study, according to fifths of free fructose intake in subgroups. Reference group for comparisons was men in lowest fifth of fructose intake and (top) with body mass index $<25 \mathrm{~kg} / \mathrm{m} 2$, (middle) no alcohol use, and (bottom) total daily dairy intake $\leq 1.6$ servings. Relative risks were adjusted for age, total energy intake, body mass index, diuretic use, history of hypertension, history of renal failure, intake of alcohol, intake of total vitamin C, and percentage of energy from total carbohydrate and protein

developed reduced insulin sensitivity and whole body glucose disposal, whereas comparable amounts of starch had no observable effects. ${ }^{37}$ In humans, reductions in insulin binding and insulin activity were observed among healthy people fed 1000 extra kilocalories as fructose for seven days, whereas intake of 1000 extra kilocalories as glucose had no similar adverse effects. ${ }^{40}$ Likewise, in another study in humans ${ }^{41}$ intake of $15 \%$ of total energy as fructose for five weeks resulted in higher insulin and glucose responses than isocaloric diets with $7.5 \%$ of energy from fructose or no fructose. Additionally, an increase in fructose consumption often leads to positive energy balance, which may contribute to excess adiposity. ${ }^{424}$ Excess adiposity is associated with a higher concentration of non-esterified fatty acids ${ }^{44}$ which might reduce 
insulin sensitivity by increasing the intramyocellular lipid content in muscle cells where insulin receptors are located. ${ }^{13}$

\section{Public health implications}

Our results have important practical implications. Over 100 years ago Osler prescribed diets low in fructose as a means to prevent gout. ${ }^{12}$ He wrote in his 1893 text $^{45}$ that "The sugar should be reduced to a minimum. The sweeter fruits should not be taken." ${ }^{12}$ Conventional dietary recommendations for gout have, however, focused on restriction of purine intake, although low purine diets are often high in carbohydrates, including fructose rich foods. ${ }^{14}$ Our data provide prospective evidence that fructose poses a substantial risk for gout, thus strongly supporting the validity and importance of Osler's approach. These data even suggest that the risk posed by free fructose intake could be at least as large as that by purine rich foods such as total meat consumption (relative risk between extreme fifths of intake $1.41^{26}$ ). Thus the conventional low purine diet approach allowing fructose intake could potentially worsen the overall net risk of gout attacks. Furthermore, because fructose intake is associated with increased serum insulin levels, insulin resistance, and increased adiposity ${ }^{936-3946}$ the overall negative health impact from fructose is expected to be larger particularly in patients with gout, who often have the metabolic syndrome $\left(63 \%{ }^{47}\right)$ and are overweight $\left(71 \%{ }^{26}\right)$. Conversely, the conventional low purine diet allowing fructose intake could have contributed to the high prevalence of metabolic syndrome observed in cross sectional studies. ${ }^{47-49}$ None the less, these findings support the importance of recommending a reduction in fructose intake in patients with hyperuricaemia and gout in order to reduce the risk of gout as well as to improve overall long term outcomes. Correspondingly, prospective cohort data indicate that higher consumption of sugar sweetened drinks is associated with excess adiposity and risk of type 2 diabetes. $^{5051}$ In contrast, higher consumption of fruits (and vegetables) is associated with a lower risk of chronic disorders, including coronary heart disease, ${ }^{5253}$ stroke,${ }^{54}$ certain types of cancer, ${ }^{55}$ cataract, ${ }^{56}$ and age related macular degeneration. ${ }^{5758}$ Furthermore, an increased intake of fruit and vegetables is one of the main components of the dietary approaches to stop hypertension (DASH) diet, which has been shown to substantially lower blood pressure. ${ }^{5960}$ Thus the latest dietary guidelines call for five to 13 servings of fruits and vegetables a day, depending on an individual's caloric intake. ${ }^{61}$ These various benefits and risks associated with individual fructose rich food items should be carefully considered in the potential public health applications of our findings.

\section{Strengths and limitations}

Our study has several strengths and potential limitations. Our study was substantially larger than previous studies on gout, ${ }^{1-2162-66}$ and we prospectively collected

\section{WHAT IS ALREADY KNOWN ON THIS TOPIC}

Sugar sweetened soft drinks contain large amounts of fructose, which is known to increase serum uric acid levels

No studies have investigated the link between these beverages and fructose intake and the risk of gout

\section{WHAT THIS STUDY ADDS}

Consumption of sugar sweetened soft drinks or fructose is associated with an increased risk of gout in men

Diet soft drinks are not associated with the risk of gout in men

and validated the dietary data. We avoided potential biased recall of diet because the data on intake were collected before the diagnosis of gout. Because dietary consumption was self reported by questionnaire, some misclassification of exposure is inevitable. The food frequency questionnaire has been extensively validated in a subsample of this cohort, however, and any remaining misclassification would have likely biased the results towards the null. The use of repeated dietary assessments in the analyses not only accounts for changes in dietary consumption over time but also decreases measurement error. ${ }^{2225}$ As in other epidemiological studies of gout, ${ }^{1-65}$ our primary definition of gout did not require observation of urate crystals in joint fluid. Although the presence of a tophus or urate crystals in joint fluid would be diagnostic of gout, ${ }^{27}$ the sensitivity of these findings is too low, especially in a study population such as ours because arthrocentesis is done infrequently. Thus its application would probably miss most of the genuine cases of gout. In our study fulfilment of six of the 11 criteria for gout from the American College of Rheumatology survey ${ }^{27}$ showed a high degree of concordance with the review of medical records, ${ }^{2}$ and the incidence rate of gout fulfilling the criteria in our cohort closely agreed with that estimated among male doctors in the Johns Hopkins precursor study (1.5 v 1.7 per 1000 person years). ${ }^{1}$ Furthermore, when we evaluated the impact of various definitions for gout our findings were robust and the magnitudes of associations tended to increase with increasing specificity of the case definition.

The restriction to health professionals in our cohort is both a strength and a limitation. The cohort of well educated men minimises the potential for confounding associated with socioeconomic status, and we were able to obtain high quality data with minimal loss to followup. Although the absolute rates of gout and distribution of dietary intake may not be representative of a random sample of US men, the biological effects of dietary intake on gout should be similar. Our findings are most directly generalisable to men aged 40 and older (the population with the highest prevalence of gout ${ }^{62}$ ) with no history of gout. Given the potential influence of female hormones on the risk of gout in women ${ }^{67}$ and an increased role of dietary impact on uric acid levels 
among patients with existing gout, ${ }^{68}$ prospective studies of these populations would be valuable.

In conclusion, our findings provide prospective evidence that consumption of sugar sweetened soft drinks and fructose is strongly associated with an increased risk of gout. Furthermore, fructose rich fruits and fruit juices may also increase the risk. In contrast, diet soft drinks were not associated with the risk of gout.

We thank Walter Willett for his critical review of the manuscript. Contributors: Both authors conceived, designed, and carried out the study, analysed the data, and critically reviewed the paper and approved the final draft for publication. HKC drafted the manuscript and is guarantor. Funding: This work was supported in part by grants from the National Institutes of Health (DK58573, AA11181, HL35464, and CA55075) and T AP Pharmaceuticals. The funding sources had no role in the design, conduct, or reporting of the study or in the decision to submit the manuscript for publication. HKC is the Mary Pack Arthritis Society of Canada chair in rheumatology.

Competing interests: None declared.

Ethical approval: This study was approved by the Partners Health Care System institutional review board; return of a completed questionnaire was accepted by the board as implied informed consent.

Provenance and peer review: Not commissioned; externally peer reviewed.

1 Roubenoff R, Klag MJ, Mead LA, Liang KY, Seidler AJ, Hochberg MC. Incidence and risk factors for gout in white men. JAMA 1991;266:3004-7.

2 Choi HK, Atkinson K, Karlson EW, Willett WC, Curhan G. Purine-rich foods, dairy and protein intake, and the risk of gout in men. $N$ Engl Med 2004;350:1093-103.

3 Choi HK, Curhan G. Gout: epidemiology and lifestyle choices. Curr Opin Rheumatol 2005;17:341-5.

4 Choi HK, Mount DB, Reginato AM. Pathogenesis of gout. Ann Intern Med 2005;143:499-516.

5 Lawrence RC, Helmick CG, Arnett FC, Deyo RA, Felson DT, Giannini EH, et al. Estimates of the prevalence of arthritis and selected musculoskeletal disorders in the United States. Arthritis Rheum 1998;41:778-99.

6 Arromdee E, Michet CJ, Crowson CS, O’Fallon WM, Gabriel SE. Epidemiology of gout: is the incidence rising? / Rheumatol 2002;29:2403-6.

7 Apovian CM. Sugar-sweetened soft drinks, obesity, and type 2 diabetes. JAMA 2004;292:978-9.

8 Block G. Foods contributing to energy intake in the US: data from NHANES III and NHANES 1999-2000. J Food Composit Anal 2004:17:439-47.

9 Gross LS, Li L, Ford ES, Liu S. Increased consumption of refined carbohydrates and the epidemic of type 2 diabetes in the United States: an ecologic assessment. Am / Clin Nutr 2004;79:774-9.

10 United States Department of Agriculture Economic Research Service report. www.ers.usda.gov/data/foodconsumption/spreadsheets/ sweets.xls (updated $15 \mathrm{Feb}, 2007$ ).

11 US Census Bureau. Health and nutrition. No 214. Per capita consumption of major food commodities: 1980 to 2001. In: Statistical abstract of the United States. Washington DC: US Census Bureau, 2003:143.

12 Nakagawa T, Tuttle KR, Short RA, Johnson RJ. Hypothesis: fructoseinduced hyperuricemia as a causal mechanism for the epidemic of the metabolic syndrome. Nat Clin Pract Nephrol 2005;1:80-6.

13 Wu T, Giovannucci E, Pischon T, Hankinson SE, Ma J, Rifai N, et al. Fructose, glycemic load, and quantity and quality of carbohydrate in relation to plasma C-peptide concentrations in US women. $\mathrm{Am} / \mathrm{Clin}$ Nutr 2004;80:1043-9.

14 Fam AG. Gout, diet, and the insulin resistance syndrome. J Rheumatol 2002;29:1350-5.

15 Emmerson BT. The management of gout. $N$ Engl / Med 1996;334:445-51.

16 Fox IH, Kelley WN. Studies on the mechanism of fructose-induced hyperuricemia in man. Metabolism 1972;21:713-21.

17 Stirpe F, Della Corte E, Bonetti E, Abbondanza A, Abbati A, De Stefano F. Fructose-induced hyperuricaemia. Lancet 1970;2:1310-1.

18 Emmerson BT. Effect of oral fructose on urate production. Ann Rheum Dis 1974:33:276-80.

19 Perheentupa J, Raivio K. Fructose-induced hyperuricaemia. Lancet 1967;2:528-31.

20 Raivio KO, Becker A, Meyer LJ, Greene ML, Nuki G, Seegmiller JE. Stimulation of human purine synthesis de novo by fructose infusion. Metabolism 1975;24:861-9.
21 Gibson T, Rodgers AV, Simmonds HA, Court-Brown F, Todd E, Meilton V. A controlled study of diet in patients with gout. Ann Rheum Dis 1983;42:123-7.

22 Rimm EB, Giovannucci EL, Stampfer MJ, Colditz GA, Litin LB, Willett WC. Reproducibility and validity of an expanded selfadministered semiquantitative food frequency questionnaire among male health professionals. Am J Epidemiol 1992;135:1114-26.

23 Willett WC, Sampson L, Stampfer MJ, Rosner B, Bain C, Witschi J, et al. Reproducibility and validity of a semiquantitative food frequency questionnaire. Am J Epidemiol 1985;122:51-65.

24 US Department of Agriculture. Composition offoods-raw, processed, and prepared. Washington, DC: USDA, 1993.

25 Feskanich D, Rimm EB, Giovannucci EL, Colditz GA, Stampfer MJ, Litin LB, et al. Reproducibility and validity of food intake measurements from a semiquantitative food frequency questionnaire. J Am Diet Assoc 1993;93:790-6.

26 Choi HK, Atkinson K, Karlson EW, Curhan G. Obesity, weight change, hypertension, diuretic use, and risk of gout in men-the health professionals follow-up study. Arch Intern Med 2005;165:742-8.

27 Wallace SL, Robinson H, Masi AT, Decker JL, McCarty DJ, Yu TF. Preliminary criteria for the classification of the acute arthritis of primary gout. Arthritis Rheum 1977;20:895-900.

28 Choi HK, Atkinson K, Karlson EW, Willett WC, Curhan G. Alcohol intake and risk of incident gout in men-a prospective study. Lancet 2004:363:1277-81.

29 Hu FB, Stampfer MJ, Manson JE, Rimm E, Colditz GA, Rosner BA, et al. Dietary fat intake and the risk of coronary heart disease in women. $N$ Engl/ Med 1997:337:1491-9.

30 Hu FB, Stampfer MJ, Manson JE, Rimm E, Colditz GA, Speizer FE, et al. Dietary protein and risk of ischemic heart disease in women. Am J Clin Nutr 1999;70:221-7.

31 Willett W. Nutritional epidemiology. 2nd ed. New York, Oxford: Oxford University Press, 1998

32 Choi HK, Curhan G. Coffee, tea, and caffeine consumption and serum uric acid level-the third national health and nutrition examination survey. Arthritis Rheum (in press).

33 Puig JG, Fox IH. Ethanol-induced activation of adenine nucleotide turnover. Evidence for a role of acetate. / Clin Invest 1984;74:936-41.

34 Faller J, Fox IH. Ethanol-induced hyperuricemia: evidence for increased urate production by activation of adenine nucleotide turnover. N Engl / Med 1982;307:1598-602.

35 Fox IH, Palella TD, Kelley WN. Hyperuricemia: a marker for cell energy crisis. N Engl J Med 1987;317:111-2.

36 Blakely SR, Hallfrisch J, Reiser S, Prather ES. Long-term effects of moderate fructose feeding on glucose tolerance parameters in rats. J Nutr 1981;111:307-14.

37 Thorburn AW, Storlien LH, Jenkins AB, Khouri S, Kraegen EW. Fructoseinduced in vivo insulin resistance and elevated plasma triglyceride levels in rats. Am J Clin Nutr 1989;49:1155-63.

38 Zavaroni I, Sander S, Scott S, Reaven GM. Effect of fructose feeding on insulin secretion and insulin action in the rat. Metabolism 1980;29:970-3.

39 Rizkalla SW, Boillot I Tricottet V, Fontvieille AM, Luo I, Salzman IL, et al. Effects of chronic dietary fructose with and without copper supplementation on glycaemic control, adiposity, insulin binding to adipocytes and glomerular basement membrane thickness in normal rats. Br/ Nutr 1993;70:199-209.

40 Beck-Nielsen H, Pedersen O, Lindskov HO. Impaired cellular insulin binding and insulin sensitivity induced by high-fructose feeding in normal subjects. Am / Clin Nutr 1980;33:273-8.

41 Hallfrisch J, Ellwood KC, Michaelis OET, Reiser S, O'Dorisio TM, PratherES. Effects of dietary fructose on plasma glucose and hormone responses in normal and hyperinsulinemic men. / Nutr 1983;113:1819-26

42 Tordoff MG, Alleva AM. Effect of drinking soda sweetened with aspartame or high-fructose corn syrup on food intake and body weight. Am I Clin Nutr 1990;51:963-9.

43 Anderson JW, Story LJ, Zettwoch NC, Gustafson NJ, Jefferson BS. Metabolic effects of fructose supplementation in diabetic individuals. Diabetes Care 1989:12:337-44.

44 McGarry JD. Disordered metabolism in diabetes: have we underemphasized the fat component? / Cell Biochem 1994:55(suppl):29-38.

45 Osler W. Gout. The principles and practice of medicine. 2nd ed. New York: Appleton, 1893:287-95.

46 Bray GA, Nielsen SI, Popkin BM. Consumption of high-fructose corn syrup in beverages may play a role in the epidemic of obesity. Am J Clin Nutr 2004;79:537-43.

47 Choi HK, Ford ES, Li C, Curhan G. Prevalence of the metabolic syndrome in patients with gout: the third national health and nutrition examination survey. Arthritis Rheum 2007;57:109-15.

48 Lee WY, Park JS, Noh SY, Rhee El, Kim SW, Zimmet PZ. Prevalence of the metabolic syndrome among 40,698 Korean metropolitan subjects. Diabetes Res Clin Pract 2004;65:143-9. 
49 Vazquez-Mellado J, Conrado GG, Vazquez SG, Medrano G, Ornelas M, Alcocer L, et al. Metabolic syndrome and ischemic heart disease in gout. J Clin Rheumatol 2004;10:105-9.

50 Schulze MB, Manson JE, Ludwig DS, Colditz GA, Stampfer MJ, Willett WC, et al. Sugar-sweetened beverages, weight gain, and incidence of type 2 diabetes in young and middle-aged women. JAMA 2004;292:927-34.

51 Ludwig DS, Peterson KE, Gortmaker SL. Relation between consumption of sugar-sweetened drinks and childhood obesity: a prospective, observational analysis. Lancet 2001;357:505-8.

52 Hung HC, loshipura KJ, Jiang R, Hu FB, Hunter D, Smith-Warner SA et al. Fruit and vegetable intake and risk of major chronic disease. J Natl Cancer Inst 2004;96:1577-84.

53 Joshipura KJ, Hu FB, Manson JE, Stampfer MJ, Rimm EB, Speizer FE, et al. The effect of fruit and vegetable intake on risk for coronary heart disease. Ann Intern Med 2001;134:1106-14.

54 Joshipura KJ, Ascherio A, Manson JE, Stampfer MJ, Rimm EB, Speizer FE, et al. Fruit and vegetable intake in relation to risk of ischemic stroke. JAMA 1999;282:1233-9.

55 Vainio H, Bianchini F. IARC handbooks of cancer prevention: fruit and vegetables. Lyon, France: International Agency for Research on Cancer, 2003.

56 Moeller SM, Taylor A, Tucker KL, McCullough ML, Chylack LTJr, Hankinson SE, et al. Overall adherence to the dietary guidelines for Americans is associated with reduced prevalence of early age-related nuclear lens opacities in women. J Nutr 2004;134:1812-9.

57 Cho E, Seddon JM, Rosner B, Willett WC, Hankinson SE. Prospective study of intake of fruits, vegetables, vitamins, and carotenoids and risk of age-related maculopathy. Arch Ophthalmol 2004;122:883-92.

58 Krinsky NI, Landrum JT, Bone RA. Biologic mechanisms of the protective role of lutein and zeaxanthin in the eye. Annu Rev Nutr 2003;23:171-201.
59 Sacks FM, Svetkey LP, Vollmer WM, Appel LJ, Bray GA, Harsha D, et al. Effects on blood pressure of reduced dietary sodium and the dietary approaches to stop hypertension (DASH) diet. DASH-Sodium Collaborative Research Group. N Engl J Med 2001;344:3-10.

60 Appel LJ, Moore TJ, Obarzanek E, Vollmer WM, Svetkey LP, Sacks FM, et al. A clinical trial of the effects of dietary patterns on blood pressure. DASH Collaborative Research Group. N Engl J Med 1997;336:1117-24

61 US Department of Agriculture. Dietary guidelines for Americans, 2005. Washington, DC, Center for Nutrition Policy and Promotion, USDA.

62 Campion EW, Glynn RJ, DeLabry LO. Asymptomatic hyperuricemia. Risks and consequences in the normative aging study. Am J Med 1987;82:421-6.

63 Shadick NA, Kim R, Weiss S, Liang MH, Sparrow D, Hu H. Effect of low level lead exposure on hyperuricemia and gout among middle aged and elderly men: the normative aging study. J Rheumatol 2000;27:1708-12.

64 Abbott RD, Brand FN, Kannel WB, Castelli WP. Gout and coronary heart disease: the Framingham study. J Clin Epidemiol 1988;41:237-42.

65 Hochberg MC, Thomas J, Thomas DJ, Mead L, Levine DM, Klag MJ. Racial differences in the incidence of gout. The role of hypertension. Arthritis Rheum 1995;38:628-32.

66 Sharpe CR. A case-control study of alcohol consumption and drinking behaviour in patients with acute gout. Can Med Assoc J 1984;131:563-7.

67 Nicholls A, Snaith ML, Scott JT. Effect of oestrogen therapy on plasma and urinary levels of uric acid. BMJ 1973;1:449-51.

68 Gibson T, Hannan SF, Hatfield PJ, Simmonds HA, Cameron JS, Potter CS, et al. The effect of acid loading on renal excretion of uric acid and ammonium in gout. Adv Exp Med Biol 1977;76B:46-56.

Accepted: 3 November 2007 